\title{
Factors associated with the nutritional status of children under-five years of age with diarrhoea in Ohangwena Region, Namibia
}

\author{
Maria Francineth Bauleth ${ }^{* 1,2}$, Honore Kabwebwe Mitonga ${ }^{1}$, Lusia Ndahambelela Pinehas ${ }^{2}$ \\ ${ }^{1}$ School of Public Health, University of Namibia, Namibia \\ ${ }^{2}$ School of Nursing, University of Namibia, Namibia
}

Received: February 9, 2020

Accepted: April 23, 2020

Online Published: May 6, 2020

DOI: $10.5430 /$ ijh.v6n2p23

URL: https://doi.org/10.5430/ijh.v6n2p23

\begin{abstract}
Purpose: This study aims at assessing the nutritional status of children under-five years of age with acute diarrhoea, determine the prevalence of malnutrition and identifying factors associated with undernutrition among children under 5 years old in Ohangwena Region, Namibia.

Methods: Cross-sectional, non-interventional study was conducted. A structured questionnaire was administered through face to face interviews. A total of 530 children under-five years from 530 households were included in this study. The nutritional index was measured based on Child Growth Standards proposed by WHO. The anthropometric measures used included mid-upper arm circumference (MUAC) and weight-for-age Z score (WAZ). Logistic regression was applied to determine the factors associated with the prevalence of malnutrition.

Results: The overall prevalence of diarrhoea among the children under-five years was $24 \%$, of these, $77 \%$ were suffering from malnutrition. Malnutrition prevalence was observed to be significantly associated with a child suffering from diarrhoea $(p<.05)$ and children aged between 12-23 months $p \leq .001$. Equally, the highest prevalence of malnutrition $29.4 \%$ [95\% CI $=24.65$; 34.15] was found amongst children under-five years old with mothers/caregivers aged 18-30 years. The strongest predictor of malnutrition was the mother/caregiver not being an educated recording odds ratio of 20.2 .

Conclusions: This study identified the need to develop and intensify strategies that may improve nutritional status in children under-five years such as health education, improved literacy, and women empowerment.
\end{abstract}

Key Words: Nutritional status, Malnutrition, Children under-five years old, Diarrhoea, Anthropometrics

\section{INTRODUCTION AND BACKGROUND}

Malnutrition remains a public health problem in most developing countries and one of the major causes of child death worldwide. In many countries, the nutritional problem has not yet resolved to the desired level, despite the effort of most government interventions to address the issue. ${ }^{[1]}$ Sk- oufias, Vinha, and Sato indicate that in 2014, 171 million children under the age of five had stunted growth. ${ }^{[2]}$ Based on a study conducted in Nepal, it was reported that nearly $37 \%$ of children were suffering from underweight, $41 \%$ from stunting and $11 \%$ were suffering from wasting. ${ }^{[3]}$ Equally, in Sub-Sahara and Africa, undernutrition is reported to be

\footnotetext{
*Correspondence: Maria Francineth Bauleth; Email: mbauleth@unam.na; Address: School of Public Health and School of Nursing, University of Namibia, Namibia.
} 
overwhelming, 58 million under-five were too short for their age and 13.9 million weighed too little for their age. ${ }^{[4]}$ Conferring to a study conducted by the Global Burden of Disease in 2016 childhood wasting was among the risk factors for diarrhoea, responsible for $80.4 \%$ of diarrheal deaths in children under five years old. ${ }^{[5]}$ According to WHO it is estimated that malnutrition is the underlying cause of 30\%-35\% death of children under five years old. ${ }^{[6]}$ Almost three-fifths of those deaths are a result of severe acute malnutrition (SAM). However, death related to malnutrition can be prevented if identified and properly managed. ${ }^{[7]}$

Malnutrition happens as a result of absolute deficiency or excess of essential nutrients whereby, under-five children are the most vulnerable group to malnutrition and micronutrient deficiency. ${ }^{[8]}$ Consequently, in the long term, children develop abnormalities related to behavioral problems, physical and mental health as well as low educational achievement. ${ }^{[9]}$ Poverty and diseases are reported to be the leading causes of malnutrition, many studies found socio-economic status to be significantly associated with malnutrition. ${ }^{[1]}$ Nevertheless, according to the World Bank, ${ }^{[10]}$ malnutrition involves multiple sectors. Instantaneous causes are associated with food and nutrient intake and health, underlying causes are rooted in the household and community context in which undernutrition occurs such as a change in climate, agricultural practices, lack of access to clean water and sanitation, caregiver education. Nonetheless, basic causes of malnutrition are imbedded in institutional, political as well as economic issues related to poverty reduction and economic growth. Moreover, for policy decisions, resource allocation, and target interventions, measurement of prevalence, incidence, and mortality associated with malnutrition and diarrheal disease is crucial. ${ }^{[11]}$

In Namibia, malnutrition remains a public health problem since independence in 1990 the levels of stunting have remained above the WHO $20 \%$ cut-off points, even though during the same period the country's economy has grown substantially. ${ }^{[12]}$ Food and nutritional insecurity is a widespread problem, Namibia can only produce $50 \%$ of its cereal needs, consequently, food is mainly imported from South Africa and sometimes from Zambia. ${ }^{[13]}$ The country is faced with recurrent droughts and floods interacting with poverty, all in all contributing to the levels of malnutrition seen in the country. According to the Namibian Demographic and Health Survey 2013 (NDHS), 24\% of children under-five years were stunted and $8 \%$ were severely stunted. Children from rural areas accounted for $28 \%$ versus $17 \%$ from urban areas respectively. However, Ohangwena Region where the current study was conducted was on the lead as compared to other regions in the country accounting for $37 \%$ of undernourished children. ${ }^{[14]}$

Anthropometric indicators commonly used to measure underfive nutritional status are as follows wasting, stunting, and underweight. ${ }^{[8]}$ Stunting is used in cases a children's height is less, relative to their age, wasting, if children weigh less, relative to their height and underweight if they weigh less, relative to their age. ${ }^{[15]}$ Weight for age below minus two standard deviations (-2SD) from the median of the reference population is regarded as underweight and the measures below minus three standard deviations (-3SD) are considered as severely underweight. ${ }^{[9]}$ Conferring to NDHS, 2013 ${ }^{[14]}$ the evaluation of anthropometric measures allows identification of children subgroups that are at increased risk of disease, faltered growth, impaired mental development and death. ${ }^{[16]}$ Furthermore, child survival can be predicted based on child nutritional status. ${ }^{[3]}$ However, assessment of malnutrition in children under-five old cannot be determined simply based on assessing the prevalence of easily recognized syndromes such as kwashiorkor or marasmus, this way might show an unrepresentative proportion of the problem, the most effective way is of detecting hidden malnutrition is by anthropometric assessment. ${ }^{[17]}$ Nevertheless, these indicators may have practical barriers in clinical measurement, meanwhile, weight measurement might be difficult or even impossible due to the non-availability of an accurate machine and well-trained health workers for measurement collection. In some instances, where kids are having illiterate mothers or are in the care of the caregivers who are not the biological mothers and not in possession of health passports which can indicate the precise age of the children. Under such circumstances precise age of the child might be unknown; therefore, the mid-upper arm circumference (MUAC) can be used as a potential proxy of weight for height (WHZ) as it is independent of age. ${ }^{[18]}$

Even though the prevalence of malnutrition in children under five years old is relatively documented in Namibian communities there is limited evidence on nature, prevalence, and factors related to child malnutrition in rural communities. The prevalent literature on child underweight in Namibia is based either on the Namibian DHS, specific health facilities ${ }^{[19]}$ or on small samples targeting few health factors. ${ }^{[14]}$ Therefore in Namibia, there is a need to carry out studies that could highlight factors associated with the nutritional status of children under five years old with diarrhoea so that effective policy could be devised to help the country achieve its Sustainable Development Goals. 


\section{MeTHOdS}

\subsection{Study design and setting}

A non-interventional cross-sectional study was conducted at a community level, in the Engela Health District in Ohangwena Region between 17 January 2019 and 9 March 2019. Ohangwena region is one of the thirteen regions situated in the northern part of the country sharing the borders with Angola. ${ }^{[20]}$ The region comprises eleven constituencies of which seven falls under the Engela Health District were the study took place. The predominant activities are small-scale agricultural land and keeping of cattle. However, this region is frequently affected by a natural disaster such as floods that occurs during heavy rains that predispose the residents to waterborne diseases as well as drought leading to famine. Engela district has one Regional hospital two health centers and 18 clinics providing health services.

\subsection{Study population}

The study population consisted of children aged 1-59 months who were residents of households from randomly selected constituencies. Exclusion criteria included households with no under-five children, children that are less than 1 month old, participants who lived in the area for less than one year and a child whose caregiver was not available at the time of interviews.

\subsection{Sampling and sample size}

Multistage sampling was used as follows: The constituencies were selected using systematic random sampling. The villages were selected using probability cluster sampling, clusters were created based on directions such as (North, South, East, and West) than purposive sampling was used to select one stratum that comprises the majority of the children under five years old, and random walk sampling technique was used by randomly choosing the village. Households were selected using probability stratified sampling, two clusters were created one consisting of household with under-five children and another that doesn't have children under-five, the cluster with under-five was purposely selected for the study. Furthermore, after identifying the first household participants were selected using the snowball method. The child that has suffered from diarrhoea in the previous two weeks before the study is purposely selected to take part in the studies. In case if there was more than one child in the household or more than one child who suffered from diarrhoea, simple random sampling was done whereby children were allocated numbers written on a piece of paper, the papers were then folded and mixed, one sample was randomly picked, and the child whose number was picked took part in the study.

Sample size was determined based on the Cochran formula Published by Sciedu Press used when population size is infinite. ${ }^{[21]}$

$n=Z^{2} * \frac{p * q}{e^{2}} \cdots n=\frac{1.96^{2} * 0.5 * 0.5}{0.05^{2}}=384 H \mathrm{H}$

$\mathrm{n}=$ sample size, $\mathrm{z}=$ desired confidence level $95 \%, \mathrm{p}=\mathrm{ex}-$ pected prevalence, $q=1-p$ (expected non-Prevalence), $\mathrm{e}=$ relative desired precision.

Non respondent rate of $10 \%=38+384=422 \mathrm{HH}$.

Hence, the minimum sample size was $422 \mathrm{HH}$, however, we managed to survey 530 households.

\subsection{Data collection procedure}

A structured questionnaire was used to collect data from households. The questionnaire was adapted from the Namibian Demographic and Health Survey (NDHS) and the Namibia Statistical Agency (NSA) Household Income and Expenditure Survey (NHIES), ${ }^{[14,22]}$ as well from other relevant literature that is related to this study and adjusted for this studies. The questionnaire consisted of three sections. Section: A socio-demographic characteristic of under-five children and mother/caregivers, section: B comprises of household characteristics, Section: C comprises of aspects related to diarrhoea and malnutrition. The questionnaire was then translated in Oshiwambo by the linguistic person and then translated back to English after data collection. The research team comprises principal the researcher, student nurses and Health Extension Workers (HEWs). Both student nurses and HEWs were trained to assist in data collection before the actual research process.

The self-report method was used to gather information whereby the researcher, student nurses and HEWs carried out data collection by moving from household to household with under-five. Respondents who were the primary caregivers, who know the child better, be it mother, father or caregiver, (male or female), were requested to provide answers based on the questions from the questionnaire. The research team also clarified where necessary and fill in the respondents' answers exactly as they were given by the respondents. The research team members, then left with the questionnaire once the respondent has finished answering all the questions. ${ }^{[23]}$

\subsection{Measurements}

In this study only two anthropometric measures were used, weight-for-age Z score (WAZ) and MUAC, because of a lack of equipment needed to measure the length (infantometer) and height board (stadiometer).

Data on the weight-for-age of children who took part in the study was collected by weighing the children who were less than five years old. In this study, children's nutritional index was measured based on Child Growth Standards as proposed 
by WHO. The anthropometric measures used WAZ, low weight for age, in children can signify the history of poor nutrition, recurrent illness and or starvation, whereas MUAC is being used as an additional screening tool. ${ }^{[24]}$

WAZ was measured with digital scales and infant scales with a precision of $0.1 \mathrm{Kg}$, nutritional status was determined based on WHO, Z-score. Children categorized as having normal nutrition when $\mathrm{Z}$-score $\geq-2 \mathrm{SD}$, moderate underweight: $-3 \leq$ Z-score <-2SD and severely underweight: Z-score $<-3$ SD. Underweight was defined as a Z-score less than -2 standard deviation of weight for age. ${ }^{[9,15]}$

MUAC was obtained from all the children who formed part of the study, taken from children who were between 6-59 months old. A non-stretchable measuring tape was used to measure MUAC, taken at a point equidistant between the acromion process of the left scapula and the olecranon process of the left ulna. Furthermore based on MUAC reading children were categorized as Normal $>13.5 \mathrm{~cm}$, mild to moderate acute malnutrition (MAM) $11.5-13.5 \mathrm{~cm}$ and $<11.5$ severe acute malnutrition $\left(\mathrm{SAM}^{[7]}\right)$.

\subsection{Data quality control}

A Pilot study was done on 19 households (5\% of the sample) in the constituency that is not part of the study, done before the actual data collection for testing validity and reliability of the instrument, and modified accordingly. Data collectors were trained before data collection and continuous supervision was carried out by the main researcher.

\subsection{Data analysis}

The analysis was based upon 530 households containing at least one under-five. Descriptive statistics were used to summarize the data which were presented as frequency distribution tables, consisting of frequencies, percentages and $95 \%$ confidence intervals. An independent sample $t$-test was conducted to compare the mean score between the sexes of under-five children. We applied Logistic regression analysis on factors associated with nutritional status of under five-year children in the Engela District, to determine the likelihood of factors that have an impact on the prevalence of malnutrition. The model containing all the predictors was statistically significant $\chi^{2}(14, \mathrm{~N}=530)=50.1451, p<.001$ this is an indication that the model was able to distinguish between children who had malnutrition and those who did not have malnutrition. We used International Business Machines (IBM) Statistical Package for Social Science (SPSS) software version 25 to perform this analysis.

\subsection{Ethical consideration}

The ethical clearance was given by the University of Namibia Research Ethics Committee (UREC) and permission to conduct the study was granted by the Namibian Ministry of Health and Social Services and the regional director for the Ohangwena Region. The Helsinki Declaration was adhered to when conducting the study. Consent was sought before interviews and mothers/caregivers were informed about the survey procedures.

\section{RESULTS}

\subsection{Socio-demographic characteristics of the children under-five years according to nutritional status}

A total number of 530 mothers/caregivers and their children participated in the study. Table 1 shows the distribution of socio-demographic characteristics of the children based on their nutritional status. Prevalence of underweight was relatively high, $66.8 \%$ of children were categorized as being underweight based on WAZ. However, based on MUAC, only $40 \%$ were categorized as being malnourished.

The age of the children ranged from 1-59 months the mean age was 23.7 months with a standard deviation of 15.1 months. To allow comparison children's age was categorized into different age groups. However, the majority of the children $26 \%$ were aged between 12-23 months old. Nevertheless, children in the age group of $48-59$ months $88.5 \%$ (95\% CI of 85.78; 91.22; $p \leq .001$ ) had a higher risk of developing underweight compared to those among other younger age groups, the observed difference was significant. Slightly more than half of the children $55.4 \%$ were females as compared to males $44.6 \%$, however, the proportion of underweight was higher $67.2 \%$ among males than females. Nevertheless, the observed difference was not statistically significant.

The majority of the children $86 \%$ received all the required vaccines based on their age, nevertheless, children whose immunization was not up to date had more risk of developing underweight $79 \%$ than those whose immunization was up to date $66 \%$, however, the observed difference was not significant. Similarly, $24 \%$ of the children were reported to have suffered from diarrhoea in the past two weeks before the survey. Nonetheless, the findings were statistically significant, whereby children who suffered from diarrhoea had a more risk $77 \%$ (95\% CI of 73.42; 80.58; $p \leq .05$ ) of developing underweight than those who did not sufferer from diarrhoea. 
Table 1. Socio-demographic characteristics of the children $<5$ years old according to WAZ

\begin{tabular}{|c|c|c|c|c|c|c|}
\hline Items & Variable & $\begin{array}{l}\text { Underweight } \\
\text { n (\%) }\end{array}$ & $\begin{array}{l}\text { No underweight } \\
\text { n (\%) }\end{array}$ & Total n (\%) & $\begin{array}{l}95 \% \text { CI for the } \\
\text { prevalence of } \\
\text { underweight }\end{array}$ & $p$-value* \\
\hline \multirow{7}{*}{$\begin{array}{l}\text { Child's age (in } \\
\text { months) }\end{array}$} & $1-11$ & $74(66.1 \%)$ & $38(33.9 \%)$ & $111(21.1 \%)$ & {$[62.07 ; 70.13]$} & \multirow{7}{*}{$\leq .001$} \\
\hline & $12-23$ & $77(56.8 \%)$ & $61(44.2 \%)$ & $138(26.0 \%)$ & {$[52.28 ; 61.02]$} & \\
\hline & $24-35$ & $63(60.0 \%)$ & $42(40.0 \%)$ & $105(19.8 \%)$ & {$[55.83 ; 64.17]$} & \\
\hline & $36-47$ & $71(73.2 \%)$ & $26(26.8 \%)$ & $97(18.3 \%)$ & {$[69.44 ; 76.97]$} & \\
\hline & $48-59$ & $69(88.5 \%)$ & $9(11.5 \%)$ & $78(14.7 \%)$ & {$[85.78 ; 91.22]$} & \\
\hline & Total & $354(66.8 \%)$ & $176(33.2 \%)$ & $529(100.0 \%)$ & {$[62.79 ; 70.81]$} & \\
\hline & \multicolumn{2}{|c|}{ Mean age (mean $\pm \mathrm{SD}$, years) } & $23.67 \pm 15.11$ & & & \\
\hline \multirow{3}{*}{ Sex of children } & Male & $157(44.4 \%)$ & $80(45.5 \%)$ & $237(44.7 \%)$ & {$[40.17 ; 48.63]$} & \multirow{3}{*}{.810} \\
\hline & Female & $197(55.6 \%)$ & $96(54.5 \%)$ & $293(55.3 \%)$ & {$[51.37 ; 59.83]$} & \\
\hline & Total & $354(66.8 \%)$ & $176(33.2 \%)$ & $530(100 \%)$ & & \\
\hline \multirow{3}{*}{ Immunization status } & Up to date & $302(66.0 \%)$ & $154(34.0 \%)$ & $456(86.0 \%)$ & {$[61.97 ; 70.03]$} & \multirow{3}{*}{$.029^{*}$} \\
\hline & Not up to date & $52(79.0 \%)$ & $22(30.0 \%)$ & $74(14.0 \%)$ & {$[75.53 ; 82.47]$} & \\
\hline & Total & $354(66.8 \%)$ & $176(33.2 \%)$ & $530(100.0 \%)$ & & \\
\hline \multirow{3}{*}{$\begin{array}{l}\text { Had diarrhoea in the } \\
\text { past two weeks before } \\
\text { the survey }\end{array}$} & Yes & $97(77.0 \%)$ & $29(23.0 \%)$ & $126(24.0 \%)$ & {$[73.42 ; 80.58]$} & \multirow{3}{*}{$.005^{*}$} \\
\hline & No & $257(64.0 \%)$ & $147(36.0 \%)$ & $404(76.0 \%)$ & {$[59.91 ; 68.09]$} & \\
\hline & Total & $354(66.8 \%)$ & $176(33.2 \%)$ & $530(100 \%)$ & & \\
\hline \multirow{2}{*}{$\begin{array}{l}\text { Nutritional status } \\
\text { based on MUAC }\end{array}$} & & Malnutrition & No malnutrition & & & \multirow{2}{*}{$.002^{*}$} \\
\hline & Total & $188(40 \%)$ & $278(60)$ & $467(100 \%)$ & {$[35.56 ; 44.44]$} & \\
\hline
\end{tabular}

Note. ${ }^{*} p$-value Pearson chi-square statistically significant .05

3.2 Socio-demographic, socio-economic characteristics of mothers/caregivers and household factors related to the prevalence of underweight in children under five years

The majority of $80 \%$ of the participants were from rural areas, $19 \%$ from the informal settlement, and the minority $1 \%$ from the urban area. Underweight was found to be more prevalent in an informal settlement, children from informal settlement had a higher risk of $74.5 \%$ of developing underweight as compared to those from other areas. However, the observed difference was not statistically significant. About $29.4 \%$ of the mothers/caregivers were aged between 18-30 years followed by $26.4 \%$ aged between 31 to 40 years. Moreover, $75 \%$ of the caregivers were unemployed with a majority of $93.2 \%$ having a monthly income of $190-2,000 \mathrm{~N} \$$ per month. Nevertheless, children from families earning between $190-2,000 \mathrm{~N} \$$ had a much higher risk of $67.6 \%$ of developing underweight as compared to other children whose mother/caregiver were earning a bit higher. However, these variables were not significantly related to the occurrence of undernutrition among children under five years old.

Based on the mother/caregiver level of education, $16 \%$ of mothers/caregivers were not educated at all, majority, $46.4 \%$ attended primary education and only a small percentage $2 \%$ attained higher education. The results were statistically significant on the association between the nutritional status and the mothers/caregivers level of education. The occurrence of underweight among children whose mothers had never attended school $76.5 \%$ (95\% CI of $72.86 ; 80.14 ; p \leq .05)$ had more risk of developing underweight as compared to those who had higher education $60 \%$ (95\% CI of 55.79; 64.21; $p<$ $.05)$.

Results show $69.3 \%$ of children suffering from underweight were from households having 10-20 inhabitant, equally $68.0 \%$ of under-five with undernutrition were from the household with nor toilet facilities. Nevertheless, the observed difference was not significantly related to the prevalence of malnutrition. Possession of television was low, only $11 \%$ of the household-owned television, however, on the other hand, $69 \%$ of the household had a radio. The majority of households owned agricultural land $62.5 \%$. However, none of the observed differences was significantly related to the occurrence of undernutrition among children. 
Table 2. Socio-demographic and socio-economic characteristics of mother/caregivers and household-related factors stratified by the occurrence of underweight in children aged $<5$ years

\begin{tabular}{|c|c|c|c|c|c|c|}
\hline Items & Variable & $\begin{array}{l}>5 \text { yrs children } \\
\text { with underweight } \\
\text { n }(\%)\end{array}$ & $\begin{array}{l}>5 \text { yrs children } \\
\text { with no } \\
\text { underweight n (\%) }\end{array}$ & Total n (\%) & $95 \% \mathrm{CI}$ & $p$-value ${ }^{*}$ \\
\hline \multirow{4}{*}{$\begin{array}{l}\text { Residence of } \\
\text { mother/careg } \\
\text { iver }\end{array}$} & Urban & $2(40 \%)$ & $3(60 \%)$ & $5(1 \%)$ & {$[35.83 ; 44.17]$} & \multirow{4}{*}{.090} \\
\hline & Informal settlement & $76(74.5 \%)$ & $26(25.5 \%)$ & $102(19 \%)$ & {$[70.79 ; 78.21]$} & \\
\hline & Rural & $276(65.2 \%)$ & $147(34.8 \%)$ & $423(80 \%)$ & {$[61.14 ; 69.26]$} & \\
\hline & Total & $354(66.8 \%)$ & $176(33.2 \%)$ & 530 & & \\
\hline \multirow{6}{*}{$\begin{array}{l}\text { Mother/careg } \\
\text { iver age } \\
\text { group }\end{array}$} & $18-30$ & $104(66.7 \%)$ & $52(33.3 \%)$ & $156(29.4 \%)$ & {$[62.69 ; 70.71]$} & \multirow{6}{*}{.971} \\
\hline & $31-40$ & $95(67.9 \%)$ & $45(32.1 \%)$ & $140(26.4 \%)$ & {$[63.83 ; 71.87]$} & \\
\hline & $41-50$ & $85(68.0)$ & $40(32.2 \%)$ & $125(23.5 \%)$ & {$[64.03 ; 71.97]$} & \\
\hline & $51-60$ & $41(65.1)$ & $22(34.9 \%)$ & $63(11.8 \%)$ & {$[61.10 ; 69.16]$} & \\
\hline & $\geq 60$ & $29(63.0)$ & $17(37 \%)$ & $46(8.6 \%)$ & {$[58.89 ; 67.11]$} & \\
\hline & Total & $354(66.8 \%)$ & $176(33.2 \%)$ & $530(100 \%)$ & & \\
\hline \multirow{5}{*}{$\begin{array}{l}\text { Employment } \\
\text { status of } \\
\text { mother/careg } \\
\text { iver }\end{array}$} & Unemployed & $265(66.9)$ & $131(33.1 \%)$ & $396(75 \%)$ & {$[62.89 ; 70.91]$} & \multirow{5}{*}{.580} \\
\hline & Employed & $31(70.5)$ & $13(29.5 \%)$ & $44(8.3 \%)$ & {$[66.82 ; 74.38]$} & \\
\hline & Self-employed & $28(68.3)$ & $14(34 \%)$ & $41(7.8 \%)$ & {$[64.32 ; 72.26]$} & \\
\hline & Famer & $29(61.7)$ & $18(38.3 \%)$ & $47(8.9 \%)$ & {$[57.56 ; 65.84]$} & \\
\hline & Total & $353(66.7 \%)$ & $176(33.2 \%)$ & $529(100 \%)$ & & \\
\hline \multirow{5}{*}{$\begin{array}{l}\text { Average } \\
\text { monthly } \\
\text { income per } \\
\text { household }\end{array}$} & $190-2,000 \mathrm{~N} \$$ & $334(67.6 \%)$ & $160(32.4 \%)$ & $494(93.2 \%)$ & {$[63.62 ; 71.58]$} & \multirow{5}{*}{.417} \\
\hline & $>2,000-5,000 \mathrm{~N} \$$ & $15(57.7 \%)$ & $11(42.3 \%)$ & $26(4.9 \%)$ & {$[51.49 ; 61.91]$} & \\
\hline & $>5,000-10,000 \mathrm{~N} \$$ & $2(40.0 \%)$ & $3(60.0 \%)$ & $5(0.9 \%)$ & {$[35.83 ; 44.17]$} & \\
\hline & $>10,000 \mathrm{NS}$ & $3(60.0 \%)$ & $2(40.0 \%)$ & $5(0.9 \%)$ & {$[55.83 ; 64.17]$} & \\
\hline & Total & $354(66.8 \%)$ & $176(33.2 \%))$ & $530(100 \%)$ & & \\
\hline \multirow{5}{*}{$\begin{array}{l}\text { Mother/careg } \\
\text { iver } \\
\text { education } \\
\text { level }\end{array}$} & Not educated & $65(76.5 \%)$ & $20(23.5 \%)$ & $85(16 \%)$ & {$[72.86 ; 80.14]$} & \multirow{5}{*}{$.015^{*}$} \\
\hline & Primary education & $154(62.6 \%)$ & $92(37.4 \%)$ & $246(46.4 \%)$ & {$[58.44 ; 66.76]$} & \\
\hline & Secondary education & $129(68.3 \%)$ & $60(31.7 \%)$ & $189(35.6 \%)$ & {$[64.34 ; 72.26]$} & \\
\hline & Higher education & $6(60 \%)$ & $4(40 \%)$ & $10(2 \%)$ & {$[55.79 ; 64.21]$} & \\
\hline & Total & $354(66.8 \%)$ & $176(33.2 \%))$ & $520(100 \%)$ & & \\
\hline \multirow{5}{*}{$\begin{array}{l}\text { Number of } \\
\text { people per } \\
\text { household }\end{array}$} & $2-4$ & $69(68.3 \%)$ & $32(31.7 \%)$ & $101(19 \%)$ & {$[64.34 ; 72.26]$} & \multirow{5}{*}{.814} \\
\hline & $5-10$ & $180(65.2 \%)$ & $96(34.8 \%)$ & $276(52 \%)$ & {$[61.14 ; 72.36]$} & \\
\hline & $10-20$ & $95(69.3 \%)$ & $42(30.7 \%)$ & $137(26 \%)$ & {$[56.37 ; 73.23]$} & \\
\hline & $>20$ & $10(62.3 \%)$ & $6(37.5 \%)$ & $16(3 \%)$ & {$[65.17 ; 66.43]$} & \\
\hline & Total & $354(66.8 \%)$ & $176(33.4 \%)$ & $530(100 \%)$ & & \\
\hline \multirow{4}{*}{ Type of toilet } & Improved & $66(64.7 \%)$ & $36(35.3 \%)$ & $102(19.2 \%)$ & {$[60.63 ; 68.77]$} & \multirow{4}{*}{.521} \\
\hline & Unimproved & $24(60.0 \%)$ & $1640.0(\%)$ & $40(7.6 \%)$ & {$[55.83 ; 64.17]$} & \\
\hline & No toilet facility & $264(68.0 \%)$ & $124(32.0 \%)$ & $388(73.2 \%)$ & {$[64.03 ; 71.97]$} & \\
\hline & Total & $354(66.8 \%))$ & $176(32.0 \%)$ & $530(100 \%)$ & & \\
\hline \multirow{3}{*}{$\begin{array}{l}\text { Ownership of } \\
\text { Television }\end{array}$} & Yes & $36(62 \%)$ & $22(37.9 \%)$ & $58(11 \%)$ & {$[57.87 ; 66.13]$} & \multirow{3}{*}{.418} \\
\hline & No & $318(67.3 \%)$ & $154(32.6 \%)$ & $472(89 \%)$ & {$[63.31 ; 71.29]$} & \\
\hline & Total & $354(66.3 \%)$ & $176(32.0 \%)$ & $530(100 \%)$ & & \\
\hline \multirow{3}{*}{$\begin{array}{l}\text { Ownership of } \\
\text { Radio }\end{array}$} & Yes & $241(66.0 \%)$ & $124(34.8 \%)$ & $365(69 \%)$ & {$[61.97 ; 70.03]$} & \multirow{3}{*}{.578} \\
\hline & No & $113(68.5 \%)$ & $52(31.5 \%)$ & $165(31 \%)$ & {$[64.55 ; 74.45]$} & \\
\hline & Total & $354(68.5 \%)$ & $176(32.0 \%)$ & $530(100 \%)$ & & \\
\hline \multirow{3}{*}{$\begin{array}{l}\text { Ownership of } \\
\text { agriculture } \\
\text { land }\end{array}$} & Yes & $212(64 \%)$ & $119(36 \%)$ & $331(62.5 \%)$ & {$[59.91 ; 68.09]$} & \multirow{3}{*}{.084} \\
\hline & No & $142(71.4 \%)$ & $57(28.6 \%)$ & $199(37.5 \%)$ & {$[67.55 ; 75.25]$} & \\
\hline & Total & $354(66.3 \%)$ & $176(32.0 \%)$ & $530(100 \%)$ & & \\
\hline
\end{tabular}

Note. ${ }^{*} p$-value Pearson chi-square statistically significant .05 
3.3 Prevalence of malnutrition measured by weight-forage and mid-upper arm circumference

Table 3 shows results related to prevalence and age distribution of undernutrition among under-five children based on the indicators used. WAZ categorized under-five $0.02 \%$ as being moderate underweight compared with MUAC 31.8\% categorized as MAM. Based on WAZ majority under five $65.2 \%$ were categorized as being severely underweight as compared to MUAC $0.02 \%$ categorized as SAM. According to WAZ, a large proportion of under-five $88.5 \%$ aged between 48-59 months were categorized as being Severe underweight. On the contrary, MUAC categorized a large proportion of $44.6 \%$ of children aged 6-12 months as having moderate malnutrition. However, these variables were found to be statistically significantly related to the occurrence of undernutrition among under-five children $(p \leq .001)$.

\subsection{Prevalence of underweight of under-five per $\mathrm{HH}$ in Engela district based on gender, 2019}

The observed difference had normal nutritional status, the mean nutritional status of under-five was $1.6679 \pm .47140$
SD. Half of 50\% were categorized as suffering from severely underweight (Z-score <-3SD). Severely underweight was more prevalent in female children under-five years $35.4 \%$ as compared to male $28 \%$. However, nutritional status based on WAZ was not statistically associated with the sex of the child $p$-value $0.728(p>.05)$. MUAC was taken from $88 \%$ of children who were between 6-59 months old, $11.5 \%$ of children were excluded since they were less than 6 months. Out of those taken MUAC $38 \%$ were categorized as suffering from moderate acute malnutrition (MAM), and the least proportion (2\%) from SAM. The mean nutritional status of under-five based on MUAC was 14.16 \pm 1.222 SD. However, nutritional status based on MUAC was found to be significantly associated with the sex of the child $(p \leq .002)$.

Comparing nutritional status and gender-based on WAZ and MUAC, both parameters indicated malnutrition to be more prevalent in under-five females, WAZ $36.2 \%$ and MUAC $23.4 \%$, as compared to males WAZ $29.4 \%$ and MUAC $16.6 \%$.

Table 3. Prevalence of undernutrition by WAZ and MUAC among 1-59 month in underweight children in the Engela District in Ohangwena region

\begin{tabular}{|c|c|c|c|c|c|c|c|c|c|}
\hline \multirow{3}{*}{$\begin{array}{l}\text { Age in } \\
\text { months }\end{array}$} & \multicolumn{4}{|c|}{ Nutritional status Z-score WAZ } & \multicolumn{4}{|c|}{ MUAC based on age category } & \multirow{4}{*}{$p$-value ${ }^{*}$} \\
\hline & Normal & Moderate & Severe & & Normal & MAM & SAM & & \\
\hline & $\begin{array}{l}\text { WAZ } \geq \\
-2 S D\end{array}$ & $\begin{array}{l}W A Z \geq \\
-3 S D \text { and } \\
<-2 S D\end{array}$ & $\begin{array}{l}\text { WAZ }< \\
-3 S D\end{array}$ & Total & $\begin{array}{l}\text { MUAC > } \\
13.5 \mathrm{~cm}\end{array}$ & $\begin{array}{l}\text { MUAC } \geq \\
115 \mathrm{~cm} \text { and } \\
<135 \mathrm{~cm}\end{array}$ & $\begin{array}{l}\text { MUAC }< \\
11.5\end{array}$ & Total & \\
\hline Age (months) & n (\%) & n (\%) & n (\%) & n (\%) & n (\%) & n (\%) & n (\%) & n (\%) & \\
\hline $\begin{array}{l}1-12 \mathrm{WAZ} \\
\text { and 6-12 } \\
\text { MUAC }\end{array}$ & $38(34.2)$ & $2(1.8)$ & $71(64.0)$ & $111(100)$ & $33(42.3)$ & $44(56.4)$ & $1(1.3)$ & $78(100)$ & \multirow{6}{*}{$\leq .001$} \\
\hline $13-23$ & $61(44.2)$ & $1(0.7)$ & $76(55.1)$ & $138(100)$ & $67(51.5)$ & $58(44.6)$ & $5(3.8)$ & $130(100)$ & \\
\hline $24-35$ & $42(40.0)$ & $2(1.9)$ & $61(58.1)$ & $105(100)$ & $65(69.1)$ & $29(30.9)$ & $0(0.0)$ & $94(100)$ & \\
\hline $36-47$ & $26(26.8)$ & $3(3.1)$ & $68(70.1)$ & $97(100)$ & $61(65.6)$ & $29(31.2)$ & $3(3.2)$ & $93(100)$ & \\
\hline $48-59$ & $9(11.5)$ & $0(0.0)$ & $69(88.5)$ & $78(100)$ & $55(74.3)$ & $18(24.3)$ & $1(1.4)$ & 74 (100) & \\
\hline Total & $176(33.3)$ & $8(0.02)$ & $345(65.2)$ & $529(100)$ & $281(59.9)$ & 149 (31.8) & $10(0.02)$ & $469(100)$ & \\
\hline
\end{tabular}

Note. ${ }^{*} p$-value Pearson chi-square statistically significant .05

3.5 Prevalence of underweight among the under-five based on the number of times child had diarrhoea in the past two weeks before the survey

Children who were categorized as being underweight 38.9\% were reported to have more than one episode of diarrhoea. Nevertheless, the majority of under-five children categorized as suffering from severe underweight $61.7 \%$ were reported to have suffered from one episode of diarrhoea one week before the survey, $21.3 \%$ two times, $10.6 \%$ three times and $6.4 \%$ had more than three times respectively (see Figure 1).
An independent samples $t$-test was conducted to compare the mean score for age, weight of under-five Z-score for age WAZ and MUAC between male and female (see Table 4). The results shows a significant difference in the mean scores of MUAC between under-five children female ( $\mathrm{MF}=14.02$, $\mathrm{SD}=1.26)$ and male $(\mathrm{MM}=14.33, \mathrm{SD}=1.15) ;(t(464)=$ $3.58, p=.01$, two-tailed). The magnitude of the difference in the means (mean difference $=-.3138$ with a $95 \%$ Confidence Interval varying between -0.54 and -0.09 ) was very large (Eta Square $=3.58)$. However, there was no significant difference in age, between female and male. Age, female $(\mathrm{M}=23.18$, 
$\mathrm{SD}=15.04)$ and male $(\mathrm{M}=23.79, \mathrm{SD}=15.35 ; t(526)=$ $-0.45, p=.65>.05$, two-tailed). The magnitude of the difference in the means (mean difference $=-0.60,95 \% \mathrm{CI}$ : -3.21 to $2.01)$ was very small $($ Eta Square $=0.0013)$. Equally, Weight was not significant different between female $(\mathrm{M}=10.05$, SD $=3.23)$ and male $(\mathrm{M}=11.05, \mathrm{SD}=8.68 ; t(526)=-1.82, p=$ 0.07 , two-tailed). Magnitude of the difference in the means (mean difference $=-1.00,95 \% \mathrm{CI}:-2.08$ to .08 ) was very small (eta square $=0.003$ ). Lastly, there was no significant difference as regard to WAZ in scores for female $(M=-7.69$, $\mathrm{SD}=18.87)$ and male $(\mathrm{M}=5.2972, \mathrm{SD}=78.02 ; t(526)=$ $-1.82, p=.61$, two-tailed). Magnitude of the difference in the means (mean difference $=-2.39,95 \% \mathrm{CI}:-11.67$ to 6.88 ) was very small (eta square $=0.00$ ). Table 5 describe the specific mean $\pm \mathrm{SD}$ of different anthropometric variables.

Table 4. Nutritional status of under-five per HH in Engela district based on gender, 2019

\begin{tabular}{|c|c|c|c|c|}
\hline $\begin{array}{l}\text { Nutritional status Z-score WAZ } \\
\text { Mean number }(\text { mean } \pm \text { SD) } 1.6679 \pm .47140\end{array}$ & $\begin{array}{l}\text { Female } \\
\text { n (\%) }\end{array}$ & $\begin{array}{l}\text { Male } \\
\text { n (\%) }\end{array}$ & $\begin{array}{l}\text { Total } \\
\text { n (\%) }\end{array}$ & $p$-value* \\
\hline Normal Nutritional Status: Z-score $\geq-2 \mathrm{SD}$ & $96(32.8)$ & $80(33.9)$ & $176(33.2)$ & \multirow{4}{*}{.728} \\
\hline Moderate Underweight: - $3 \leq \mathrm{Z}$-score $<-2 \mathrm{SD}$ & $4(1.4)$ & $4(1.7)$ & $8(1.5)$ & \\
\hline Severely underweight: Z-score $<-3 \mathrm{SD}$ & $192(65.9)$ & $152(64.4)$ & $346(65.3)$ & \\
\hline Total & $292(100)$ & $236(100)$ & $530(100)$ & \\
\hline \multicolumn{5}{|l|}{ MUAC } \\
\hline \multicolumn{5}{|l|}{ Mean number (mean \pm SD) $14.16 \pm 1.222$} \\
\hline Normal Nutritional Status : $>13.5 \mathrm{~cm}$ & $145(31.0)$ & $134(29.0)$ & $279(60.0)$ & \multirow{4}{*}{$.002^{*}$} \\
\hline Moderate Acute Malnutrition: $11.5-13.5 \mathrm{~cm}$ & $102(22.0)$ & $76(16.0)$ & $178(38.0)$ & \\
\hline Severe Acute Malnutrition: $<11.5$ & $7(1.4)$ & $3(0.6)$ & $10(2.0)$ & \\
\hline Total & $254(54.4)$ & $213(45.6)$ & $467(100 \%)$ & \\
\hline
\end{tabular}

Note. ${ }^{*} p$-value Pearson chi-square statistically significant .05

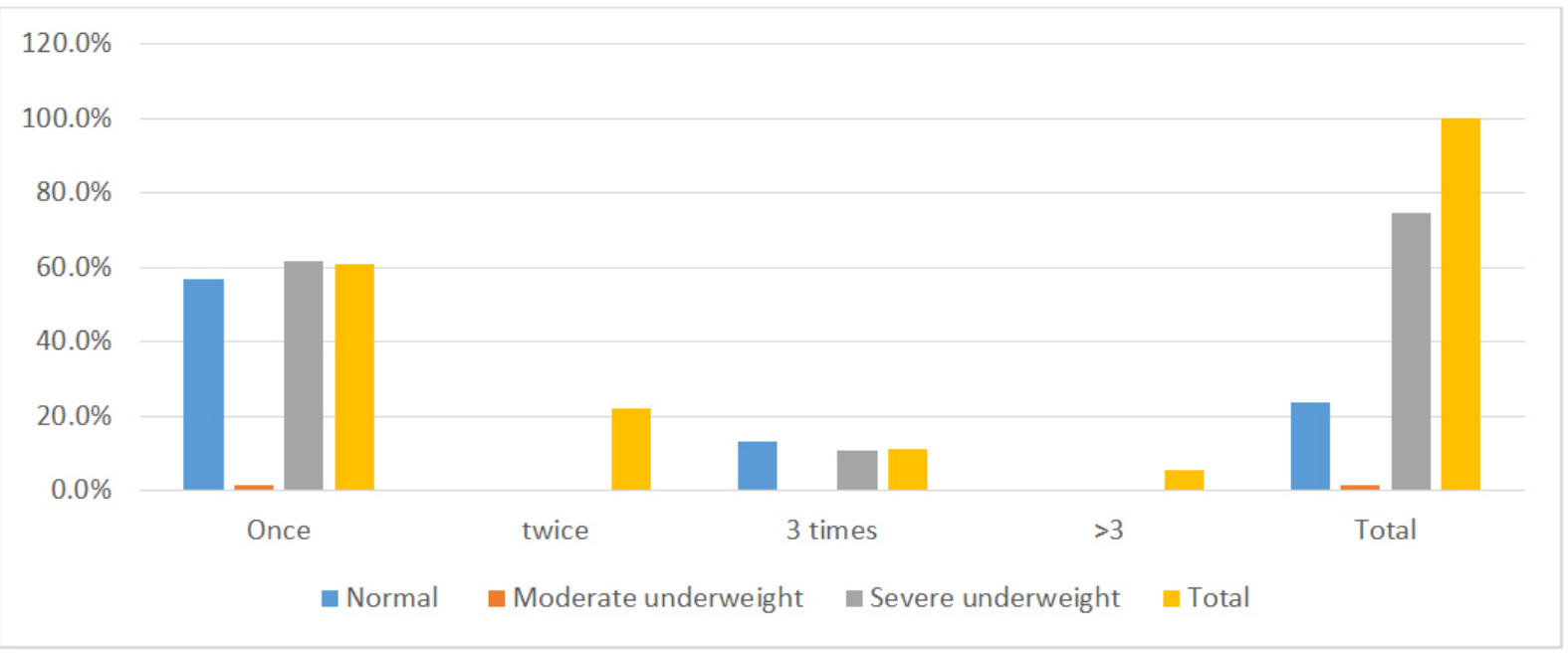

Figure 1. Number of times child had diarrhoea in past 2 weeks prior to the survey

3.6 Factors associated with nutritional status of underfive year children

Logistic regression analysis of factors associated with the nutritional status of children under-five years in the Engela District was performed to assess the likelihood of factors that have an impact on the prevalence of malnutrition. The model containing all the predictors was statistically significant $\chi^{2}$ $(14, \mathrm{~N}=530)=50.15, p<.001$ this is an indication that the model was able to distinguish between children who had malnutrition and those who did not have malnutrition. The model as a whole explained between $68.4 \%$ (Cox and Sell R square) and $94 \%$ (Nagelkerke R squared) of the variance in nutritional status and correctly classified $98 \%$ of the cases. According to the results shown in Table 5 in the dependent variable that made a unique statistically significant contribution to the model was only three (age of the under-five, sex of the under-five and weight of the under-five). The strongest predictor of malnutrition was mother/caregiver not being ed- 
ucated recording an odds ratio of 20.01. This indicates that for residence in the informal settlement was less than 1 , this mothers/caregivers who are not educated were twenty times more likely to have a child suffering from malnutrition as indicates that under-five residing in the informal settlement compared to those that are educated. The odds ratio of .001 were .001 times less likely to have malnutrition, controlling for other factors in the model (see Table 6).

Table 5. Anthropometric characteristics of under-five children by gender

\begin{tabular}{|c|c|c|c|c|c|c|}
\hline \multirow[b]{2}{*}{ Characteristics } & \multicolumn{2}{|c|}{ Gender } & \multirow[b]{2}{*}{$t$} & \multirow[b]{2}{*}{$p$-value ${ }^{*}$} & \multirow[b]{2}{*}{ Lower } & \multirow[b]{2}{*}{ Upper } \\
\hline & $\begin{array}{l}\text { Female } \\
\mathbf{n}=\text { mean } \pm \text { SD }\end{array}$ & $\begin{array}{l}\text { Male } \\
\mathrm{n}=\text { mean } \pm \mathrm{SD}\end{array}$ & & & & \\
\hline Age (months) & $293=23.18 \pm 15.04$ & $235=23.79 \pm 15.35$ & -0.45 & .65 & -3.21 & 2.01 \\
\hline Weight (Kg) & $293=10.05 \pm 3.24$ & $235=11.05 \pm 8.68$ & -1.82 & .07 & -2.078 & 0.08 \\
\hline WAZ & $293=-7.69 \pm 18.87$ & $235=-5.30 \pm 78.02$ & -0.51 & .61 & -11.67 & 6.88 \\
\hline MUAC (cm) & $258=14.01 \pm 1.26$ & $208=14.33 \pm 1.15$ & -2.78 & $.01^{*}$ & -0.54 & -0.09 \\
\hline
\end{tabular}

Note. WHZ, weight for age, MUAC, Mid upper Arm Circumference. ${ }^{*} p$-value Pearson chi-square statistically significant .05

Table 6. Logistic Regression - Factors associated with nutritional status of under 5 children aged less

\begin{tabular}{|c|c|c|c|c|c|c|c|c|}
\hline \multirow{2}{*}{ Variable } & \multirow{2}{*}{ B. } & \multirow{2}{*}{ SE } & \multirow{2}{*}{ Wald } & \multirow{2}{*}{ df } & \multirow{2}{*}{ Sig. } & \multirow{2}{*}{ Exp. (B) } & \multicolumn{2}{|c|}{ 95\% CI for Exp. B } \\
\hline & & & & & & & Lower & Upper \\
\hline Residence area & & & 2.40 & 2 & 0.30 & & & \\
\hline Informal settlement & -7.20 & 27.65 & 0.00 & 1 & 1.00 & 0.00 & 0.00 & \\
\hline Rural & -1.84 & 1.19 & 2.40 & 1 & 0.12 & 0.16 & 0.02 & 1.63 \\
\hline Age of caregiver & 0.03 & 0.03 & 1.18 & 1 & 0.28 & 1.03 & 0.97 & 1.10 \\
\hline Age of under-five in months & 1.08 & 0.19 & 33.41 & 1 & 0.00 & 3.00 & 2.05 & 4.27 \\
\hline Sex of under-five $1(1)$ & -3.88 & 1.00 & 15.24 & 1 & 0.00 & 0.02 & 0.00 & 0.15 \\
\hline Mother/caregiver education level & & & 1.38 & 3 & 0.71 & & & \\
\hline Not educated & 3.00 & 2.60 & 1.33 & 1 & 0.25 & 20.01 & 0.12 & 32.46 \\
\hline Primary education & 2.38 & 2.40 & 0.98 & 1 & 0.32 & 10.80 & 0.10 & 12.87 \\
\hline Secondary education & 2.46 & 2.37 & 1.08 & 1 & 0.30 & 11.76 & 0.11 & 15.24 \\
\hline Number of under-five per household & -0.13 & 0.39 & 0.12 & 1 & 0.73 & 0.88 & 0.41 & 1.86 \\
\hline Number of people per household & -0.00 & 0.08 & 0.00 & 1 & 0.99 & 1.00 & 0.85 & 1.18 \\
\hline Income per household & 0.00 & 0.00 & 1.28 & 1 & 0.26 & 1.00 & 1.00 & 1.00 \\
\hline MUAC in $\mathrm{cm}$ & 0.00 & 0.01 & 0.06 & 1 & 0.81 & 1.00 & 0.97 & 1.04 \\
\hline $\begin{array}{l}\text { Under-five } 1 \text { has suffered from } \\
\text { diarrhea in the past two weeks( } 1 \text { ) }\end{array}$ & 0.65 & 0.86 & 0.57 & 1 & 0.45 & 1.92 & 0.35 & 10.37 \\
\hline Weight of under-five number & -5.62 & 0.97 & 33.73 & 1 & 0.00 & 0.00 & 0.00 & 0.02 \\
\hline
\end{tabular}

\section{Discussion}

Malnutrition in children under five years old continues to be a major health problem in developing countries including Namibia. In developing countries, children are at risk of developing malnutrition because of inadequate dietary intakes, shortage of appropriate care, recurrent infectious diseases and unequal distribution of food. ${ }^{[25]}$ The current study aimed to assess the nutritional status of children $<5$ years old with acute diarrhoea and determine the prevalence and associated factors with malnutrition among children in Engela District in the Ohangwena Region. To assess the nutritional status and the effect of diarrhoea on malnutrition of under-five, anthropometric indices were investigated among 530 children > 5 years from November 2018 to February 2019. Data on the diarrheal disease was provided by the mother/caregiver interviewed. Children's nutritional status was classified based on anthropometric criteria WAZ and MUAC.

The current study based on WAZ revealed a majority of $66.7 \%$ of ( $95 \%$ CI: $62.7 \%-70.7 \%$ ) of under-five children 
were underweight, respectively in the study area. However, findings related to MUAC were much less $40 \%$ (95\% CI: $35.6 \%-44.4 \%$ ) as compared to results related to WAZ.

Even though MUAC and WHZ are commonly used in programs providing care to severely malnourished children, inconsistencies have been reported as regard identifying children as severely wasted. ${ }^{[26,27]}$ The discrepancy between the two indicators is as well reported to vary in different settings. Based on the results of the current study, about MUAC and WAZ there is a discrepancy between children who fall below the cut-off points for diagnosis of malnutrition. However similar discrepancies were observed in studies that used WHZ and MUAC for diagnosis of malnutrition. ${ }^{[28]}$

According to the current study results based on both WAZ and MUAC indicated figures that were very high according to WHO classification. ${ }^{[29]}$ The findings of the current study are in line with the DHS, 2013 that indicates that Ohangwena is one of the regions in the country with a high prevalence of undernutrition $13.7 \% .{ }^{[14]}$ However, the figures related to underweight (WAZ) and malnutrition (MUAC) are much high $66.7 \%$ and $40 \%$ compared to DHS 2013 findings of $13.7 \%$. Nevertheless, according to UNICEF in 2010, it was reported that almost one out of every three Namibian children aged under five was malnourished. ${ }^{[30]}$ Furthermore, the two anthropometric indicators of severe underweight $65.3 \%$ and severe acute malnutrition $(2 \%)$ did not identify the same population of children, different results were obtained by using WAZ parameters versus MUAC parameters. However, based on the Namibian 2013 DHS, 24\% of children underfive years were stunted and $8 \%$ were severely stunted. ${ }^{[14]}$ According to a study conducted in a rural hospital in Kenya, assessing severe malnutrition in children based on MUAC as well as WHZ, it was suggested that MUAC may be more appropriate than WHZ for identifying severe malnutrition in under-five. ${ }^{[31]}$ It is evident that the coverage of life-saving interventions across the country is uneven, there are disparities among population subgroups, in rural areas where the study has taken place, $66.7 \%$ percentages of under-five were categorized as suffering from severe malnutrition.

According to anthropometric indicators WAZ, and MUAC under-five female $35 \%$ and $16 \%$, had the highest incidences of undernutrition as compared to males $29 \%$ and $16 \%$. The incidence of malnutrition abased MUAC was found to be significantly associated with the sex of the child with $p \leq$ .001. The findings are in line with a study conducted in the rural area of Vidarbha region. The majority of children were categorized as stunted $42.9 \%$ with females being on the lead $45.5 \%$ and males $41.1 \%{ }^{[1]}$ More so, many researchers found more growth retardation in girls than in boys, which was more apparent from 12 months. They also found that growth pattern was related to feeding pattern geared by cultural perceptions. ${ }^{[1,3,24,32]}$

Nevertheless, the majority $80 \%$ of the respondents in this study are from villages who survive mostly from agricultural lands, and of which $34.8 \%$ were underweight. Malnutrition could be related to recurrent drought in the country and subsequently crop failure in the area that resulted in longlasting food insecurity and cyclical nutritional emergencies as well as natural disaster such as floods that occurs during heavy rains that predisposes the residents to waterborne diseases. $^{[2,33]}$ The difference could as well be related to socioeconomic, an additional explanation could as that the study was conducted during consecutive drought season, failure to harvest for two consecutive years could pose a big challenge to the communities who mainly survive from harvesting their fields. According to study conduct in Mexico exploring impacts of weather the health of vulnerable groups such as under-five children, unusual rainfall and temperature ware reported having an impact on the child's height for age. ${ }^{[34]}$

Incidence of malnutrition among children under five years old was found to be higher among children with mothers/caregivers aged between $18-50$ years (66.7\%-68\%) as compared to children who had mothers/caretakers aged 5160 years and above $(65.1 \%-63 \%)$. However, the proportion of children who had mothers/caregivers who were young aged between $18-30$ years was higher $29.4 \%$ (95\% CI = $24.7 \%-34.2 \%$ ) as compared to children who had caretakers aged 60 years and above $8.6 \%(95 \% \mathrm{CI}=5.3 \%-11.1 \%)$ (see Table 2).

Furthermore, according to literature the most significant contributors to under-five malnutrition in Namibia are inappropriate feeding practices, poor hygiene, and sanitation as well as poor nutrition and health status of mothers. ${ }^{[30]}$ In the current study, malnutrition was found to be significantly related to age. Malnutrition was found to be more prevalent in the age group between 12-23 months old accounting for $26 \%$ (95\% CI: $22.4-29.8 \% p \leq .001){ }^{[34]}$ Factor such as mother/caregiver education was significantly associated with undernutrition. This could be possible as a result that educated mothers could have a better understanding related to health issues and could as well practice better healthpromoting behaviors. These findings are in line with a study conducted in Northeast Ethiopia. ${ }^{[8]}$ In the current study child suffering from diarrhoea in the past two weeks was significantly associated with the increasing prevalence of malnutrition $77 \%$ underweight $(p<.05)$. This could be a result of the depleting of nutrients from the body, poor digestion, lower 
appetite and malabsorption. ${ }^{[8]}$ Literature indicates that malnourished children are more likely to have more diarrhoeal episodes and a child with diarrhoea can quickly become malnourished due to weight loss. ${ }^{[8]}$ The synergistic relationship between malnutrition and infectious diseases is documented in the literature. Infection is reported to adversely affect the under-five nutritional status, through a decrease in dietary intake and intestinal absorption, however, malnutrition, on the other hand, induces alteration in the host immune function, putting the host at risk of infections including diarrhoea. ${ }^{[36]}$ According to the current study, $61 \%$ of the children with severe underweight had one episode of diarrhoea, $21.3 \%$ had two episodes, $10.6 \%$ had three episodes and $6.4 \%$ had more than one episode of diarrhoea, however, the episodes of diarrhoea was not found to be statistically insignificant.

Moreover, the information related diarrhoea in the past two weeks preceding the research was provided by the caregiver/mothers. Therefore, the possible effect recall biases on our results cannot be ignored. Furthermore, the weight of the under-five children, as well as mid-arm circumference, was taken by different participants (researcher, student nurses and HEWs) and different weighing scales were used.

\section{Conclusion}

In conclusion, our study illustrates various factors associated with the nutritional status of under-five years of children with acute diarrhoea in the Ohangwena Region. We found evidence showing children suffering from diarrhoea had severe malnutrition, which can negatively impact the under-five mortality rate in the region. The authors recommend initiations of nutritional programs at antenatal clinics (ANC) to cater to food security and access to well-balanced diets. Additionally, we suggest giving high priority to breastfeeding mothers and caregivers to the social grant. We identified factors contributing to malnutrition in under-five children. Our findings suggest health education to be provided to mothers postnatal before being discharged from labor wards as well as during immunization follow-ups and at pediatric out-patient. Findings demonstrate that the immunization status children under the care of grandparents are not up to date. Social workers, nurses and HEWs may conduct outreach programs to feel the gaps in immunizations. Health education should include the nutritional requirements and the quantity of food need at a specific age group. Health education at the ANC should include appropriate feeding practices with available local food with high protein and lipids. Furthermore, the Health Extension Workers will play a critical role in educating the community particularly the mothers and caregivers on the preventative measures and home management of diarrhoea. The Government with the help of non-governmental organizations should ensure the availability of supplementary food to reduce malnutrition in under-five year children. Also, clinical training activities for diarrheal disease management should consider the inclusion of the various caregiving local settings. Consequently, interventions such as water treatment, improved sanitation, hygiene and nutrition interventions, poverty eradication and improvement in the education level of the caregivers/mothers need to be given attention more so in remote areas.

\section{Data AVAilability}

The data used to support the findings of this study are available from the corresponding author upon request.

\section{ACKNOWLEDGEMENTS}

We would like to thank the Ohangwena Regional Director Mr. John Hango for grating us permission to conduct this study in the region. We greatly appreciated the sister's incharge of clinics and health centers in the Engela district for facilitating contact with the Institution Health Workers and for availing them to participate in data collection.

\section{CONFliCtS OF INTEREST Disclosure}

The authors declare that they have no conflicts of interest.

\section{REFERENCES}

[1] Gajbhiye A, Vellhal G, Mathew M, et al. To assess the prevalence of malnutrition among the children of the age group of 0-5 years in the rural area of Vidarbha region. Panacea Journal of Medical Sciences. 2018; 8(2): 88-92. https://doi.org/10.18231/234 8-7682.2018.0020

[2] Skoufias E, Vinha K, Conroy HV. The impacts of climate variability on welfare in rural Mexico. Policy Research Working Papers - World Bank. 2011. https://doi.org/10.1596/1813-9450-5555

[3] Chataut J, Khanal K. Assessment of Nutritional Status of Children Under Five years of age in rural Nepal. Kathmandu Univ Med J
(KUMJ). 2016; 14(1): 73-77.

[4] Skoufias E, Vinha K, Sato R. All Hands on Deck Reducing Stunting through Multisectoral. Washington DC, 2019. PMid:31488701. https://doi.org/10.1596/978-1-4648-1396-2

[5] Bill F, Foundation MG. Estimates of the global, regional, and national morbidity, mortality, and aetiologies of diarrhoea in 195 countries: a systematic analysis for the Global Burden of Disease Study 2016. Lancet Infect Dis. 2018; 18: 1211-1228.

[6] WHO. Regional Progress in Survival of Newborn, Children, and Mother: Moving Towards Global Strategy Target. 2018.

[7] Tadesse AW, Tadesse E, Berhane Y, et al. Comparison of mid-upper 
arm circumference and weight-for-height to diagnose severe acute malnutrition: A study in Southern Ethiopia. Nutrients. 2017; 9(3). PMid:28287482. https : //doi.org/10.3390/nu9030267

[8] Gebre A, Reddy PS, Mulugeta A, et al. Prevalence of Malnutrition and Associated Factors among Under-Five Children in Pastoral Communities of Afar Regional State, Northeast Ethiopia: A CommunityBased Cross-Sectional Study. J Nutr Metab. 2019; 2019: 9187609. PMid:31275645. https ://doi.org/10.1155/2019/9187609

[9] Acquah E, Darteh EKM, Amu H, et al. Predictors of underweight in children under-five years in Ghana. Ghana Med. J. 2019; 53(1): 71-78. PMid:31138947. https ://doi.org/10.4314/gmj . v53i1.11

[10] World B. Improving Nutrition Through Multisectoral Approaches. 2013.

[11] Troeger C, Colombara DV, Rao PC, et al. Articles Global disabilityadjusted life-year estimates of long-term health burden and undernutrition attributable to diarrhoeal diseases in children younger than 5 years. Lancet Glob. Heal. 2018; 6(3): e255-e269. https : //doi.org/10.1016/S2214-109X (18)30045-7

[12] Survey E. Unicef annual report for Namibia. 2015; 1990.

[13] National Planning Commission. The root causes of Poverty. 2010; 37-41.

[14] Ministry of Health and Social Services. Namibia Demographic and Health Survey 2013. Windhoek, Namibia, 2014.

[15] Tariq J, Sajjad A, Zakar R, et al. Factors associated with undernutrition in children under the age of two years: Secondary data analysis based on the Pakistan demographic and health survey 2012-2013. Nutrients. 2018; 10(6): 1-20. PMid:29861467. https : //doi.org/10.3390/nu10060676

[16] Senthilkumar SK, Chacko TV, Suvetha K. Nutritional status assessment of children aged 0-5 years and its determinants in a tribal community of Coimbatore district. Int. J. Community Med. Public Heal. 2018; 5(7): 2835. https://doi .org/10.18203/2394-604 $0 . i \mathrm{jcmph} 20182610$

[17] Srinivasa SB, Dnyaneshwar B, Ajay U. Anthropometric Measure ment of Weight for Assessment of Nutritional Status of Anganwadi Children in Urban Mangalore - A Cross-Sectional Study. Anat. Physiol. 2017; 7(3): 3-7. https : //doi .org/10.4172/2161-0940.10 00259

[18] Asif M, Aslam M, Altaf S. Evaluation of nutritional status of children using mid-upper arm circumference (MUAC): A study from Pakistan. Pakistan Paediatr. J. 2017; 41(3): 163-167.

[19] Haludilu T, Hangula T, Nauiseb P. Investigation on the factors associated with undernutrition. 2017.

[20] N.S.A. Ministry of Health and Social Services, Namibia Population and Housing Census. Ohangwena 2011 Census Regional Profile. 2011.

[21] G.U. mathematics Association, Chapter 2 Determination of appropriate Sample Size. Int. J. Appl. Math. Stat. Sci. 2013; 2(1): 3-38.
[22] Namibia Statistics Agency. Namibia Household Income and Expenditure Survey. Windhoek, Namibia, 2016.

[23] Polit C, Beck DF. Nursing Research: Generating and Assessing Evidence for Nursing Practice, 9th ed. London England: Lippincott W, Wilkins, 2012.

[24] Gupta M, Jindal R. Assessment of Nutritional Status of Under Five Children attending outpatient department at a tertiary Care Hospital: a study from North India. Int. J. Sci. Res. Educ. 2016; 4(5): 5283-5287. https://doi.org/10.18535/ijsre/v4i05.01

[25] Teferi MB, Hassen HY, Kebede A, et al. Prevalence of Stunting and Associated Factors among Children Aged 06-59 Prevalence of Stunting and Associated Factors among Children Aged 06-59 Months In Southwest Ethiopia: A Cross-Sectional Study. J. Nutr. Heal. Food Sci. 2017; 1-6. https : //doi.org/10.15226/jnhfs. 2016.00180

[26] Arnaud Laillou FTW, Sophonneary P, Richard de G, et al. Optimal Screening of Children with Acute Malnutrition Requires a Change in Current WHO Guidelines as MUAC and WHZ Identify Different Patient Groups. PLoS One. 2014; 9(7): e101159. PMid:24983995. https://doi.org/10.1371/journal.pone.0101159

[27] WHO; UNICEF. WHO child growth standards and identification of severe acute malnutrition in infants and children. 2009.

[28] Grellety E, Golden MH. Circumference should be used independently to diagnose acute malnutrition: policy implications. BMC Nutr. 2016; 1-17. https : //doi.org/10.1186/s40795-016-0049-7

[29] Yalew BD, Amsalu BM. Prevalence and Factors Associated with Stunting, Underweight and Wasting: A Community Based CrossSectional Study among Children Age 6-59 Months. Journal of Nutritional Disorders \& Therapy. 2014; 4(2).

[30] Angula N. Malnutrition in Namibia: the Time To Act Is Now. 2010.

[31] Berkley J, Mwangi I, Griffiths K, et al. Assessment of Severe Malnutrition Among Hospitalized Children in Rural Kenya: comparison of weight for height and mid upper arm circumference. JAMA. 2005; 294(5): 591-597. PMid:16077053. https ://doi.org/10.1001/ jama. 294.5.591

[32] Tumilowicz A, Habicht JP, Pelto G, et al. Gender perceptions predict sex differences in growth patterns of indigenous Guatemalan infants and young children. Am. J. Clin. Nutr. 2015; 102(5): 1249-1258. PMid:26423387. https://doi.org/10.3945/ajcn.114.10077 6

[33] International Federarion of Red Cross and Red Crescent Societies. Emergency Plan of Action Final Report. 2018; 2016.

[34] Conroy HV. The Impacts of Climate Variability on Welfare in Rural Mexico. 2011.

[35] Sunil TS, Sagna M. Decomposition of childhood malnutrition in Cambodia. Matern. Child Nutr. 2015; 11(4): 973-986. PMid:23316784. https://doi.org/10.1111/mcn. 12029

[36] Bahartha AS, Alezzi JI. Risk factors of diarrhea in children under 5 years in Al-Mukalla, Yemen. Saudi Med J. 2015; 36(6): 720-724. PMid:25987115. https ://doi.org/10.15537/smj . 2015.6.11 266 